Research Paper

\title{
Bufalin-loaded bovine serum albumin nanoparticles demonstrated improved anti-tumor activity against hepatocellular carcinoma: preparation, characterization, pharmacokinetics and tissue distribution
}

\author{
Huiqing Zhang ${ }^{1, *}$, Nian Huang ${ }^{1, *}$, Geliang Yang ${ }^{1}$, Qing Lin ${ }^{1}$ and Yonghua Su ${ }^{1}$ \\ ${ }^{1}$ Changhai Hospital of Traditional Chinese Medicine, Second Military Medical University, Shanghai 200433, China \\ *These authors have contributed equally to this work \\ Correspondence to: Yonghua Su, email: suyh2001@126.com \\ Keywords: Bufalin, bovine serum albumin, nanoparticles, hepatocellular carcinoma \\ Received: November 08, $2016 \quad$ Accepted: June 02, $2017 \quad$ Published: June 28, 2017 \\ Copyright: Zhang et al. This is an open-access article distributed under the terms of the Creative Commons Attribution License 3.0 \\ (CC BY 3.0), which permits unrestricted use, distribution, and reproduction in any medium, provided the original author and source \\ are credited.
}

\section{ABSTRACT}

Objective: To prepare and evaluate the liver-targeted drug delivery system of Bufalin with higher liver uptake and stronger antitumor activity against hepatocellular carcinoma.

Methods: Bufalin-loaded bovine serum albumin nanoparticle was prepared by desolvation method, to investigate the in vitro release performance and to evaluate the pharmacokinetic and tissue distribution. The antitumor activity against hepatocellular carcinoma was evaluated in vitro and in vivo, respectively.

Results: The Bufalin-loaded bovine serum albumin nanoparticle with an average particle size of $125.1 \mathrm{~nm}$ exhibited a sustained release behavior in vitro. The half-life, blood plasma area under the curve and apparent volume of distribution of Bufalinloaded bovine serum albumin nanoparticle were significantly higher than that of Bufalin, whereas the clearance rate was lower than Bufalin group. The uptake of liver for Bufalin-loaded bovine serum albumin nanoparticle was $352.045 \pm 35.665 \mathrm{ng} / \mathrm{g}$ while for Bufalin was $164.465 \pm 48.080 \mathrm{ng} / \mathrm{g}(P<0.01)$ at $5 \mathrm{~min}$. The uptake of tumor for Bufalin-loaded bovine serum albumin nanoparticle was significantly higher than that of Bufalin both at $5 \mathrm{~min}(50.169 \pm 11.708 \mathrm{ng} / \mathrm{g}, 93.415 \pm 13.828 \mathrm{ng} / \mathrm{g}, P<0.01)$ and $15 \mathrm{~min}(43.683 \pm 11.499 \mathrm{ng} / \mathrm{g}, 64.219 \pm 17.684 \mathrm{ng} / \mathrm{g}, P>0.05)$. Bufalin-loaded bovine serum albumin nanoparticle and Bufalin have similar antitumor activity in vitro. The tumor inhibition effect of Bufalin-loaded bovine serum albumin nanoparticle was stronger than that of Bufalin alone in vivo.

Conclusion: Bufalin-loaded bovine serum albumin nanoparticle is a promising liver-targeted drug delivery system with higher liver uptake and stronger antitumor activity against hepatocellular carcinoma.

\section{INTRODUCTION}

Hepatocellular carcinoma (HCC), one of the most common malignancies worldwide, is a malignant tumor with the fifth highest incidence and the third highest mortality tumor in the world [1]. Despite the available treatment options for $\mathrm{HCC}$, long-term survival rate of patients with $\mathrm{HCC}$ is still far from satisfactory due to a high incidence of recurrence after surgery $[2,3]$. Approximately $70 \%$ of patients who undergo potentially curative procedures will have recurrent or advanced-stage disease within five years [4]. Thus, effective therapies are required for patients with advanced HCC.

In recent years, the potential antitumor activity of natural products used in traditional Chinese medicine (TCM) has received much attention [5-7]. Chansu 
(Venenum bufonis), an important antitumor drug obtained from the skin secretions of Bufo bufo gargarizans Cantor or B. melsanostictus Schneider, has been used for thousands of years in China [8, 9]. Huachansu (Cinobufacini), a sterilized hot water extract of dried toad skin, has been approved by the Chinese Food and Drug Administration (ISO9002) and widely used to treat variety of cancers in many China's cancer centers at present, including $\mathrm{HCC}[10,11]$. Bufalin (3-b,14-Dihydroxy-5beta-bufa-20,22-dienolide; Figure 1A), a typical digoxinlike immunoreactive component, is the primary bioactive ingredient of Chansu, dried toad skin and Huachansu. A large number of studies have shown that Bufalin could produce a marked anti-tumor effect in different tumors [12-17]. Multiple anti-tumor activities of Bufalin have been recognized, such as inhibition of cell proliferation, induction of cell differentiation, induction of apoptosis, disruption of cell cycle, inhibition of cancer angiogenesis and reversal of multi-drug resistance in cancer cells $[8,12$, 14-16, 18, 19]. However, insolubility in water, toxicity, fast metabolize rate and short elimination half-life limit its wide clinical application [20]. It is urgent to develop a drug delivery system that could overcome the above problem of Bufalin while maintaining or enhancing potency.

Nanoparticulate drug delivery system is making a significant contribution to the improvement of drug delivery in cancer $[21,22]$. Targeted nanoparticulate drug delivery systems, especially biodegradable nanoparticles, provides opportunities to meet these existing challenges, with the advantages of improved pharmacokinetics, favored tumor accumulation, and reduced side effects [23-25].

Albumin has been used as a versatile protein carrier to fabricate nanoparticles for drug delivery due to its nontoxic, non-immunogenic, biocompatible and
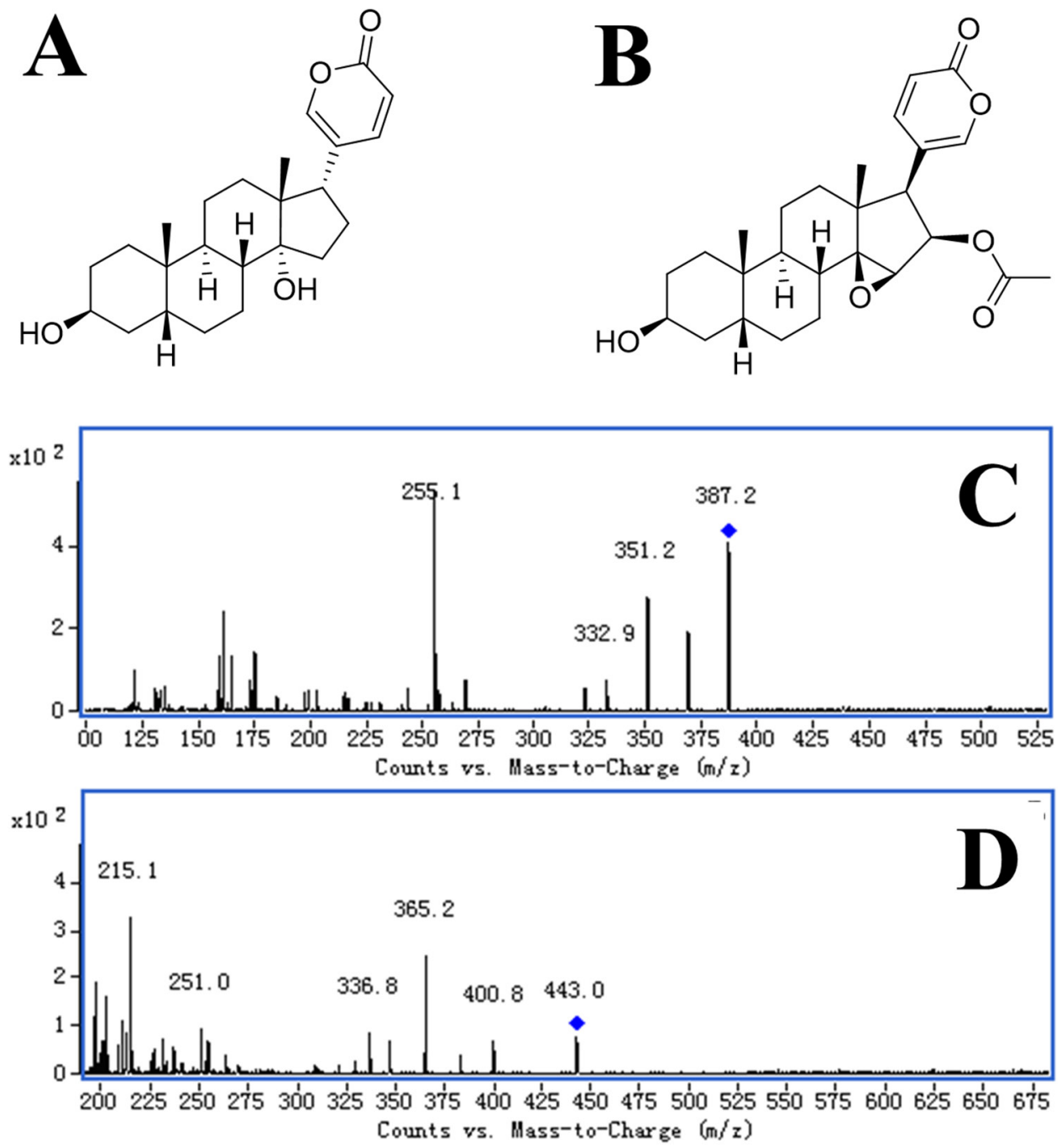

Figure 1: The chemical structure and product ion of Bufalin and Cinobufagin. (A) Chemical structure of Bufalin; (B) chemical structure of Cinobufagin; (C) product ion of Bufalin; (D) product ion of Cinobufagin. 
biodegradable properties [26]. Bovine serum albumin (BSA) is extensively used for drug delivery because of its abundance, low cost, ease of purification, unusual ligand binding properties and its wide acceptance in the pharmaceutical industry [27].

Bufalin-loaded bovine serum albumin nanoparticles have been firstly prepared by our research group with national invention patent (China, No. 00510110061.4). In this study, we have prepared Bufalin-loaded bovine serum albumin nanoparticles (Bufalin-BSA-NP) by desolvation method and evaluated its effect on antitumor, pharmacokinetic and bio-distribution.

\section{RESULTS}

\section{Preparation and characterization of Bufalin-BSA-NP}

In this study, the Bufalin-BSA-NP was prepared by desolvation method and its particle morphology was screened by transmission electron microscope (TEM). As shown in Figure 2A, Bufalin-BSA-NP had a uniform spherical morphology with the diameter of 50-250 nm. Quantative analysis of drug loading and encapsulation efficiency of Bufalin-BSA-NP and determination were finished by RP-HPLC method. The retention time of Bufalin is about $4 \mathrm{~min}$, which can be easily identified (Figure 2B). Based on the results, the linear equation of concentration of Bufalin sample (X) and peak area (Y) can be expressed as: $\mathrm{Y}=-431.79+17658.04 \mathrm{X}$, $r>0.9999$. Satisfactory linear relationship can be observed in the range of $2.5-50 \mu \mathrm{g} / \mathrm{ml}$. The encapsulation efficiency is $76.02 \%$ and drug-loading rate is $12.62 \%$. The mean particle size and polydispersity index of prepared Bufalin-BSA-NP were determined to be 125.1 $\mathrm{nm}$ and 0.140 , respectively (Figure 2C). Zeta potential of the reconstituted Bufalin-BSA-NP was determined to be $-19.24 \mathrm{mV}$. In vitro release of Bufalin-BSA-NP was metered by balance dialysis with semi-permeable membrane dialysis bag. The release curve of BufalinBSA-NP is shown in Figure 2D. The first $3 \mathrm{~h}$ belongs to burst release stage with an accumulative release of $59.16 \%$ and then a much slower release rate appears. After 6-8 h, the accumulative release rate increased to $100 \%$, which indicates that the Bufalin-BSA-NP has excellent controlled release function in vitro. In addition, about $7.34 \%$ of drug has been released after $0.5 \mathrm{~h}$, which compiles to the Pharmacopoeia of China $(<40 \%)$. In vitro release equation of Bufalin-BSA-NP can be expressed as: $\ln \ln [1 /(1-\mathrm{Q})]=-1.4092+0.9581 \operatorname{lnt},(\mathrm{r}=0.9535)$, which is determined by Weibull equation. Bufalin is insoluble in water, while Bufalin-BSA-NP has good solubility. The aqueous solution of Bufalin-BSA-NP is light yellow and clear liquid.

\section{Acute toxicity of Bufalin-BSA-NP}

The $\mathrm{LD}_{50}$ of Bufalin-BSA-NP was $4.377 \mathrm{mg} / \mathrm{kg}$ (relative concentration of Bufalin), and its $95 \%$ confidence interval (CI) was 3.765-5.099 mg/kg, while that of Bufalin was $2.739 \mathrm{mg} / \mathrm{kg}$ (95\% CI: 2.351-3.191 mg/kg). Between the groups of Bufalin-BSA-NP and Bufalin, there are no abnormal changes of major organs in naked eyes after the gross anatomy. Results of HE staining pathology showed no obvious pathological changes in liver, heart, spleen, lung, kidneys and brain in the low dose. When the Bufalin group was in $2.25 \mathrm{mg} / \mathrm{kg}$ dose, the mice's liver, heart and kidneys appeared oedema, while the Bufalin-BSA-NP group was in $4.23 \mathrm{mg} / \mathrm{kg}$ dose appear. When the drug is at high doses, the two different groups of mice's heart, liver, spleen, lung, kidneys, brain and other major organs are all have different degrees of pathological changes, among of the organs, the heart, liver and kidneys manifest the most serious degree, and their pathological changes are similar. In addition, the Figure 3 showed that the BufalinBSA-NP caused less damage to heart, liver and kidneys. From the perspective of death in mice caused by the both injection, the death time of Bufalin-BSA-NP group extended obviously than Bufalin group. The group of the highest dose of Bufalin turns up fastest death time in 2-3 min after the treatment, while Bufalin-BSA-NP group appears fastest death time in 6-7 $\mathrm{min}$ at the same dose.

\section{Pharmacokinetic study of Bufalin-BSA-NP}

Six groups of Wistar rats were treated with BufalinBSA-NP and Bufalin at a single dose of 0.6, 0.3 and $0.15 \mathrm{mg} / \mathrm{kg}$, respectively. Figure $4 \mathrm{~A}, 4 \mathrm{~B}$, and $4 \mathrm{C}$ showed the Bufalin plasma concentration-time curves after intravenous administration of different formulations. Compared with Bufalin-BSA-NP groups, Bufalin was quickly removed from the circulating system. No Bufalin was detected after $4 \mathrm{~h}$, while Bufalin-BSA-NP was still present in the plasma until 10h post-injection of BufalinBSA-NP and Bufalin. The nanoparticles showed a markedly delayed blood clearance with higher Bufalin concentration at later time points. Mean pharmacokinetic parameters of Bufalin-BSA-NP and Bufalin were listed in Figure 4A, 4B, and 4C. The pharmacokinetic parameters were calculated using noncompartmental methods. As could be seen from Table 1, The blood plasma area under the curve (AUC), mean residence time (MRT), half-life and clearance rate of Bufalin-BSA-NP were 1.19-1.81, 2.12-3.61, 2.17-2.94 and 0.55-0.82 times of Bufalin solution, respectively.

\section{Tissue distribution of Bufalin-BSA-NP}

The concentration of Bufalin in plasma and tissue were investigated after intravenous administration of Bufalin and Bufalin-BSA-NP in Wistar rats bearing 

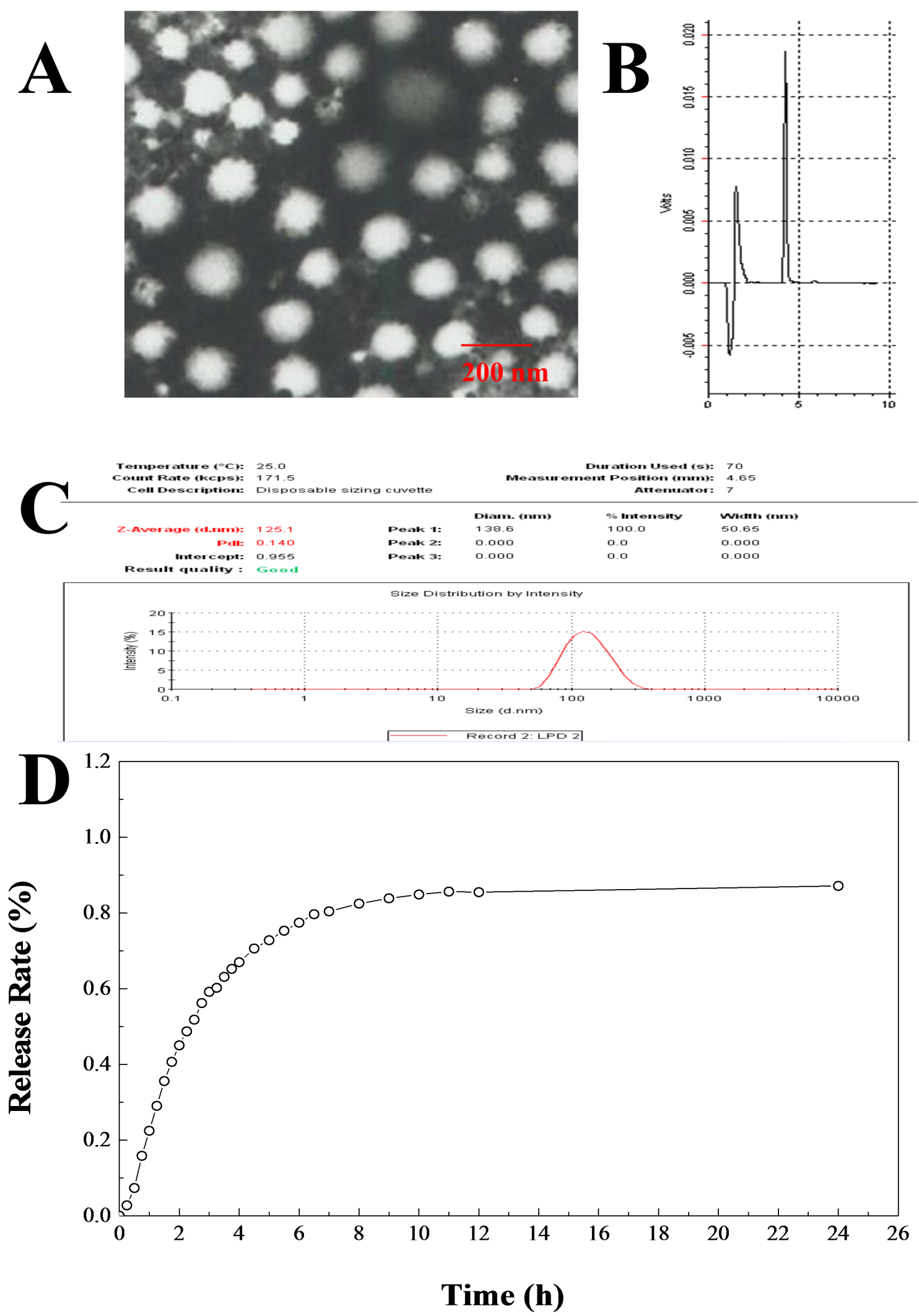

Figure 2: Characterization and physicochemical properties of Bufalin-BSA-NP. (A) The transmission electron microscope photograph of Bufalin-BSA-NP; (B) HPLC results of Bufalin-BSA-NP; (C) size distribution by intensity of Bufalin-BSA-NP; (D) release curve of Bufalin-BSA-NP in vitro. 
Walker-256 transplanted liver cancer. The concentration of Bufalin was shown in Figure 4D, 4E and 4F. As shown in Figure 4D, 4E and 4F, concentration of Bufalin in plasma after injection with Bufalin-BSA-NP was higher than that of Bufalin solution at the later time points, which was in agreement with the result of pharmacokinetics in rats. The level of Bufalin concentration of BufalinBSA-NP group was lower than that of Bufalin group in all tissue except the liver, tumor and spleen. Especially, the level of Bufalin concentration of Bufalin group was markedly higher than that of Bufalin-BSA-NP group in liver. The uptake of liver for Bufalin-BSA-NP was $352.045 \pm 35.665 \mathrm{ng} / \mathrm{g}$ and $164.465 \pm 48.080 \mathrm{ng} / \mathrm{g}$ for Bufalin $(P<0.01)$ at $5 \mathrm{~min}$. Moreover, the liver uptake of Bufalin-BSA-NP was also higher than that of Bufalin $(174.138 \pm 16.404 \mathrm{ng} / \mathrm{g}$ versus $37.689 \pm 7.860 \mathrm{ng} / \mathrm{g}, P<$
0.01). This might possibly due to the passive targeting ability of BSA nanoparticles for enhanced permeability and retention (EPR) effect [28]. Furthermore, the uptake of tumor for Bufalin-BSA-NP was significantly higher than that of Bufalin both at $5 \mathrm{~min}(50.169 \pm 11.708$ versus $93.415 \pm 13.828, \mathrm{ng} / \mathrm{g}, P<0.01)$ and $15 \mathrm{~min} 43.683 \pm$ 11.499 versus $64.219 \pm 17.684, P>0.05)$. Interestingly, the uptake of heart, lung and kidney for Bufalin-BSA-NP were all lower than that of Bufalin. For administration of Bufalin-BSA-NP at $5 \mathrm{~min}, 72.537 \pm 9.916,77.087$ \pm 13.965 , and $61.396 \pm 18.126 \mathrm{ng} / \mathrm{g}$ of Bufalin were distributed in liver, heart and kidney, respectively. In contrast, for the same time period of Bufalin, $29.695 \pm$ $6.314,26.919 \pm 3.358$, and $25.638 \pm 7.657 \mathrm{ng} / \mathrm{g}$ of Bufalin were distributed in the above organs, respectively. These results obviously demonstrated that Bufalin-BSA-NP was
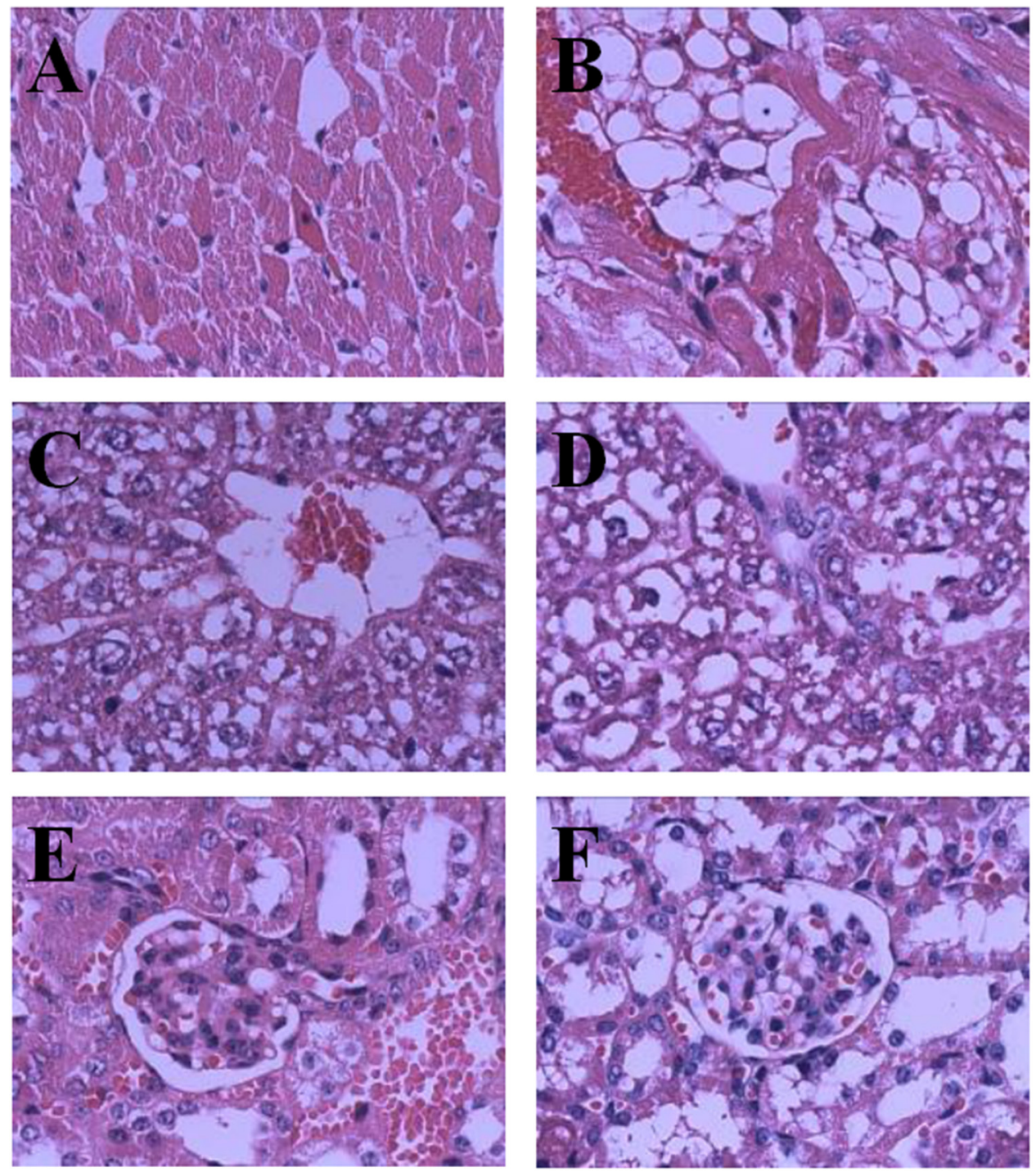

Figure 3: Pathology changes in HE staining (HE×400). (A) 8mg/kg Bufalin-BSA-NP Heart; (B) 8mg/kg Bufalin Heart; (C) 8mg/ kg Bufalin-BSA-NP Liver; (D) 8mg/kg Bufalin Liver; (E) 8 mg/kg Bufalin-BSA-NP kindey; (F) 8 mg/kg Bufalin kindey. 
superior to Bufalin since Bufalin-BSA-NP could deliver more Bufalin to both liver and tumor and reduce the toxicity to heart, lung and kidney.

\section{Bufalin-BSA-NP demonstrated similar anti-tumor effects to Bufalin in vitro}

As plotted in Figure 5, the cellular inhibition effect of Bufalin-BSA-NP on cell of SMMC-7721 is similar with Bufalin. From analyzing the cell viability, there is a statistical difference on different concentrations or point in time inhibition rate $(P<0.01$ or $P<0.05)$, but did not reflect obviously the both on the strength of interaction. The inhibition rate to a certain range $\left(10^{-6}-10^{-8} \mathrm{~mol} / \mathrm{L}\right)$ increases with the increase of concentration. When the concentration of Bufalin-BSA-NP was more than $10^{-6}$ $\mathrm{mol} / \mathrm{L}$ levels, each period inhibitory rate did not increase significantly. With Loggt method, geting role for $24 \mathrm{~h}$, $\mathrm{IC}_{50}$ of Bufalin-BSA-NP is $1.81 \times 10^{-7} \mathrm{~mol} / \mathrm{L}$ while that of Bufalin is $1.56 \times 10 \mathrm{~mol} / \mathrm{L}(P>0.05)$. When for $48 \mathrm{~h}, \mathrm{IC}_{50}$ of the both are respectively $1.12 \times 10^{-8} \mathrm{~mol} / \mathrm{L}$ and $2.33 \times$ $10^{-8} \mathrm{~mol} / \mathrm{L}$.
A

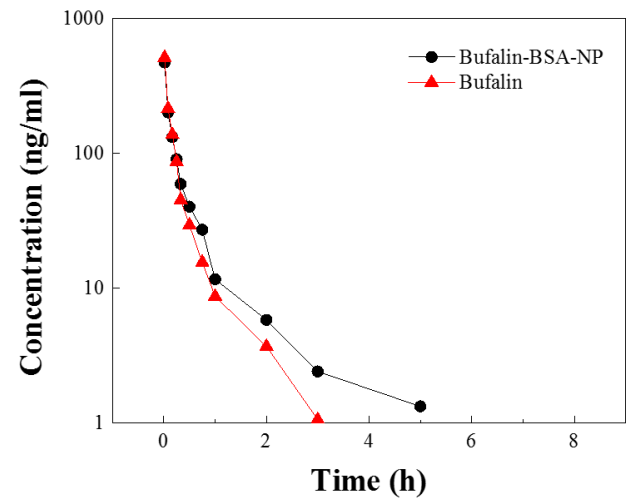

$\mathcal{C}$

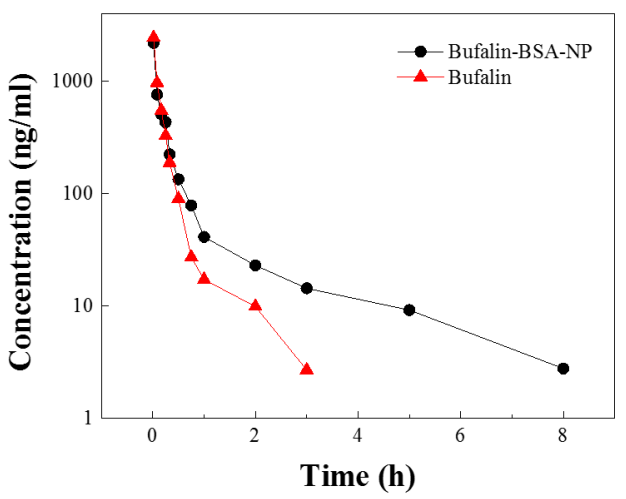

$\mathbf{E}$

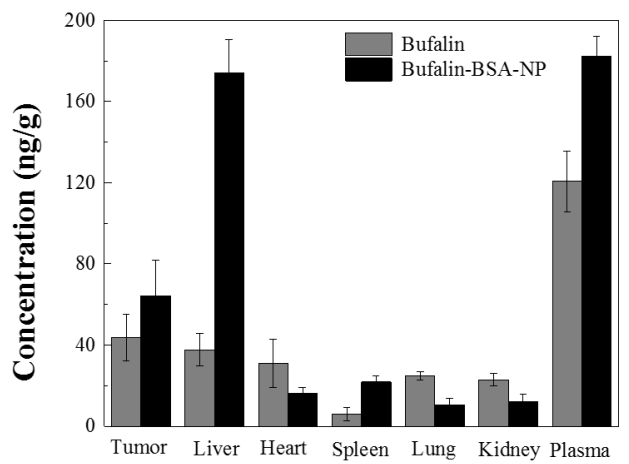

B

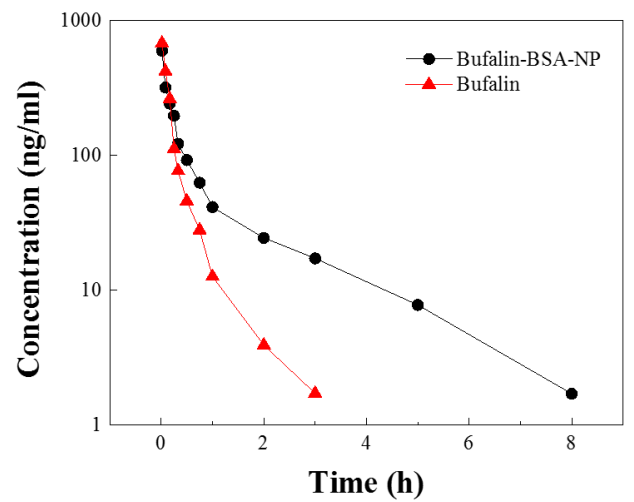

D
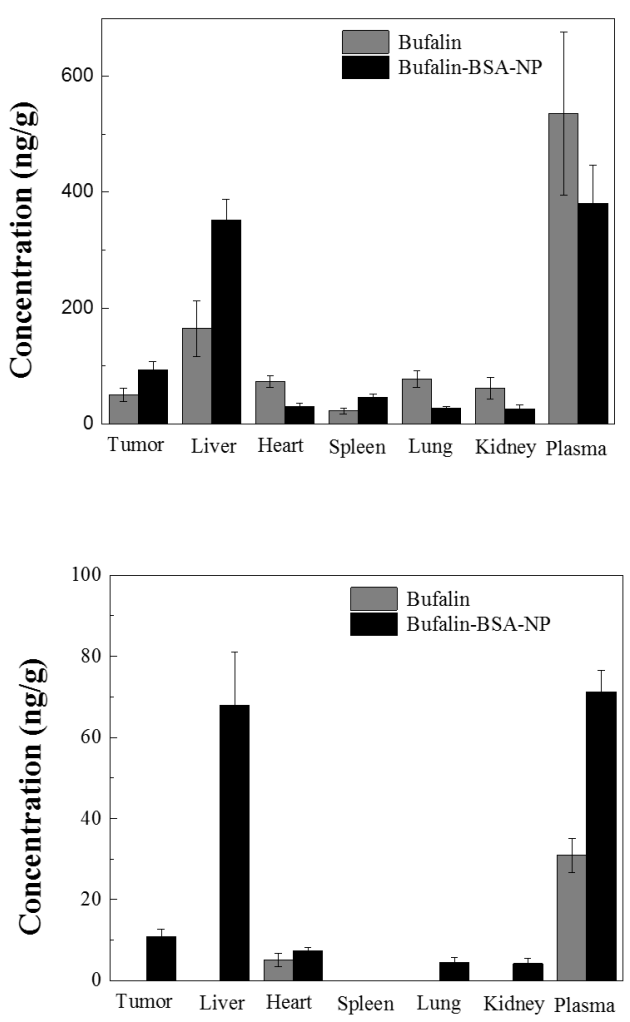

Figure 4: Pharmacokinetic and tissue distribution of Bufalin-BSA-NP in vivo. (A, B, C) Bufalin concentration of Bufalin and Bufalin-BSA-NP at doses of 0.15 (A), 0.3 (B) and 0.6 (C) $\mathrm{mg} / \mathrm{kg}$, respectively; (D, E, F) tissue distribution of Bufalin and Bufalin-BSA-NP in vivo at 5,15 , and $45 \mathrm{~min}$ after a single dose of $0.3 \mathrm{mg} / \mathrm{kg}$. Values are expressed as mean \pm standard error of mean; $n=5$. 
Table 1: Pharmacokinetic parameters of Bufalin and Bufalin-BSA-NP at doses of $0.15,0.3 \mathrm{and} 0.6 \mathrm{mg} / \mathrm{kg}$

\begin{tabular}{|c|c|c|c|c|c|c|}
\hline \multirow{2}{*}{$\begin{array}{l}\text { Pharmacokinetic } \\
\text { parameters }\end{array}$} & \multicolumn{2}{|c|}{$0.6(\mathrm{mg} / \mathrm{kg})$} & \multicolumn{2}{|c|}{$0.3(\mathrm{mg} / \mathrm{kg})$} & \multicolumn{2}{|c|}{$0.15(\mathrm{mg} / \mathrm{kg})$} \\
\hline & Bufalin & Bufalin-BSA-NP & Bufalin & Bufalin-BSA-NP & Bufalin & Bufalin-BSA-NP \\
\hline$C_{\max }(\mathrm{ng} / \mathrm{mL})$ & 2430.5 & 2186.2 & 682.3 & 599.9 & 515.6 & 474.3 \\
\hline$t_{1 / 2}(\min )$ & 43.2 & 127.2 & 39 & 93 & 34.8 & 75.6 \\
\hline MRT (min) & 19.2 & 68.4 & 24.6 & 88.8 & 24 & 51 \\
\hline $\mathrm{AUC}_{0-8}(\mathrm{ng} \mathrm{h} / \mathrm{mL})$ & 299.7 & 380.8 & 126.6 & 229.6 & 77.6 & 92.5 \\
\hline $\mathrm{AUC}_{0-\infty}(\mathrm{ng} \mathrm{h} / \mathrm{mL})$ & 302.6 & 389.7 & 128.22 & 233.48 & 78.53 & 94.98 \\
\hline $\mathrm{Vd}(\mathrm{L} / \mathrm{kg})$ & 0.64 & 1.76 & 0.95 & 1.90 & 0.76 & 1.34 \\
\hline $\mathrm{CL}(\mathrm{L} / \mathrm{h} \mathrm{kg})$ & 2.00 & 1.54 & 2.34 & 1.29 & 1.93 & 1.58 \\
\hline
\end{tabular}

Bufalin-BSA-NP: Bufalin-loaded bovine serum albumin nanoparticle; $\mathrm{t}_{1 / 2}$ : half-life of plasma; $C_{\max }:$ maximum concentration; MRT: mean residence time; AUC: area under the curve; Vd: aparent volume of distribution; CL: clearance.
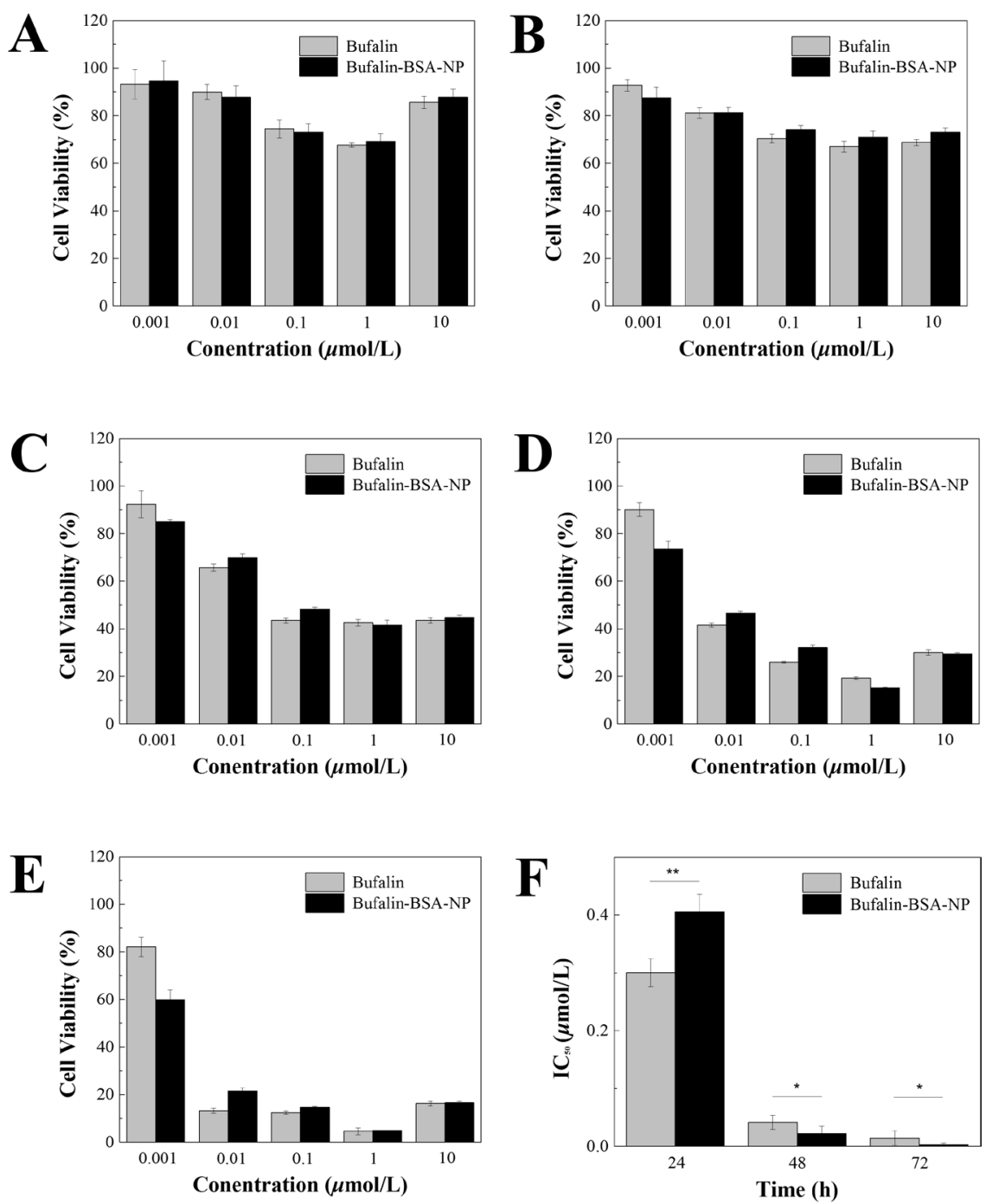

Figure 5: Bufalin-BSA-NP demonstrated similar anti-tumor effects to Bufalin in vitro. (A) The cell viability after sustained action of $6 \mathrm{~h}$; (B) the cell viability after sustained action of $12 \mathrm{~h}$; (C) the cell viability after sustained action of $24 \mathrm{~h}$; (D) the cell viability after sustained action of $48 \mathrm{~h}$; (E) the cell viability after sustained action of $72 \mathrm{~h}$; (F) half inhibitory concentration (IC ${ }_{50}$ ) of Bufalin-BSANP. Values are expressed as mean \pm standard error of mean; $n=5$. ${ }^{*} P<0.05 ; * * P<0.01$. 


\section{Bufalin-BSA-NP demonstrated more potent anti-tumor effects than Bufalin on hepatocellular carcinoma in nude mice}

In the in vivo tumor inhibition test, there were significant differences in the tumor mass in the BufalinBSA-NP and Bufalin groups $(P<0.05$; Figure 6$)$. The difference between each group was also significant $(P<0.05)$, suggesting that both Bufalin-BSA-NP and Bufalin alone could suppress cancer of the liver, although the tumor inhibition effect of Bufalin-BSA-NP was stronger than that of Bufalin alone. After treatment, the weight of three groups (Bufalin, Bufalin-BSA-NP and adriamycin) and NS group have significant differences. Among them, the weight of Bufalin and Bufalin-BSANP group increased significantly, whereas the weight of normal saline (NS) and adriamycin (ADM) group are significantly reduced. The group of ADM compared with before and after treatment, the weight significantly reduction $(P<0.01)$. Mice skin fold obviously, the group of ADM life status is the worst, and diet, activity is significantly reduced; while Bufalin, Bufalin-BSA-NP, NS group of nude mice living conditions is better, diet, activity is basic normal, and Bufalin and Bufalin-BSA-NP group of weight increase than pre-dose, NS group weight change is not obvious.

Most mice in each group died within $45 \mathrm{~d}$ after administration. From Figure 6, compared with NS and ADM groups, the average survival time of the mice with orthotopic transplantation liver cancer model administered Bufalin-BSA-NP and Bufalin have been extended $(P<$ $0.05)$. In addition, the survival time of Bufalin-BSA-NP have lengthened slightly compared with Bufalin group. However, the difference is not statistically significant $(P>0.05)$. Compared with NS group, ADM group does not prolong survival time without statistically significant difference.

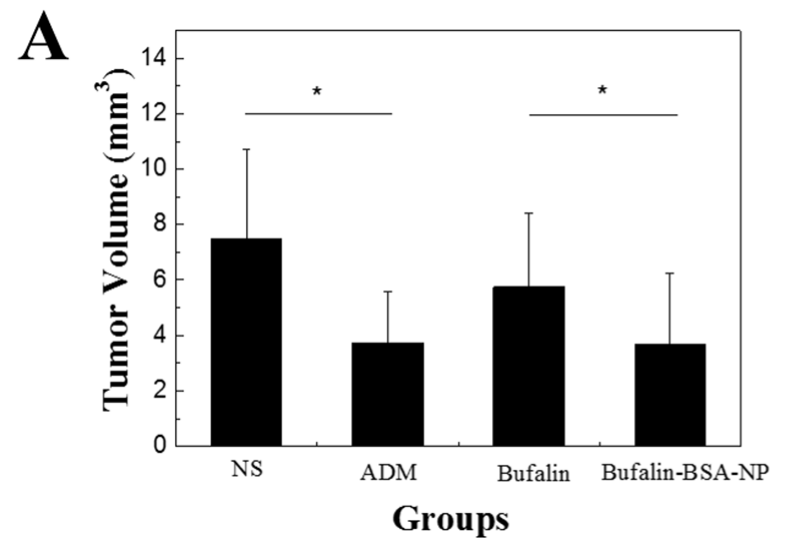

\section{DISCUSSION}

In the present study, Bufalin-BSA-NP was successfully prepared as a liver-targeted drug delivery system. In vitro release profiles of Bufalin from BufalinBSA-NP exhibited a sustained release behaviour. A similar phenomenon was also observed in the in vivo pharmacokinetic study.

Compared with Bufalin solution, Bufalin-BSA-NP showed higher AUC value and a prolonged residence of drug in blood circulation. Moreover, higher drug concentration and longer residence time of Bufalin in liver demonstrated that Bufalin-BSA-NP could directly target to liver and reduce the side effects of Bufalin to other organs.

Our results showed that the micellar size obtained in size distribution by intensity was consistent with the results of TEM. Particle size and its distribution are the most widely accepted defining characteristics of nanoparticlebased medicines since particle size can significantly influence the pharmacokinetics, biodistribution, and safety of nanoparticulate drugs [29].

The acute toxicity data indicated that the toxicity of Bufalin-BSA-NP is lower than that of Bufalin. The harmacokinetic behaviour of Bufalin-BSA-NP displayed significantly higher AUC (p50.05) and slower clearance (p50.05) than that of Bufalin solution, indicating that Bufalin-BSA-NP increased the systemic circulation time and a higher amount of Bufalin available for tissue uptake. These results given above were related to the metabolic pattern of Bufalin in vivo, which was in agreement with the in vitro sustained release of Bufalin from the nanoparticles. When Bufalin solution was injected into the vein, Bufalin was directly exposure to blood, resulting in faster elimination. However, the nanoparticles can serve as reservoirs for Bufalin in blood, which prevent the interactions between Bufalin and the blood components. When Bufalin-BSA-NP was gradually

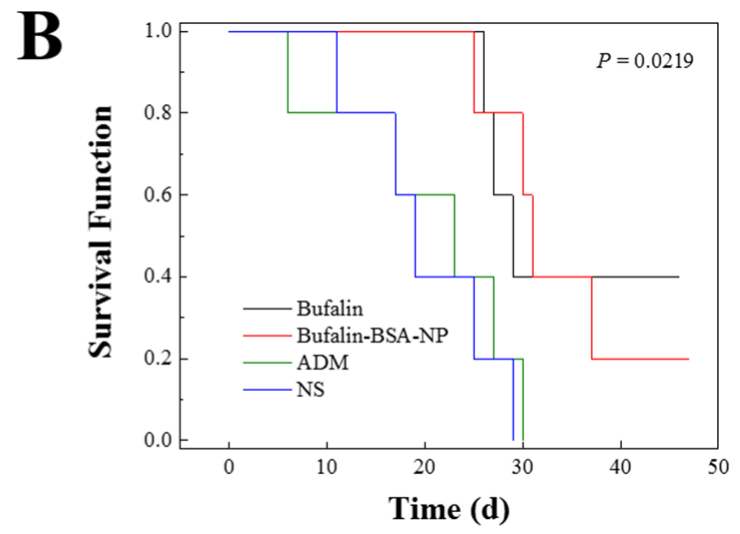

Figure 6: Bufalin-BSA-NP demonstrated more potent anti-tumor effects than Bufalin on hepatocellular carcinoma in nude mice. (A) Tumor volume of different groups; (B) survival analysis of different groups. ADM: adriamycin; NS: normal saline. Values are expressed as mean \pm standard error of mean; $n=10 . * P<0.05$. 
Table 2: The optimized MRM parameters for Bufalin and Cinobufagin

\begin{tabular}{lcccc}
\hline Group & Precursor ion & Fragmentor energy (V) & Collision energy (eV) & Production \\
\hline Bufalin & 387.2 & 180 & 22 & 255.1 \\
Cinobufagin & $\mathbf{4 4 3 . 2}$ & $\mathbf{1 3 5}$ & $\mathbf{1 8}$ & $\mathbf{3 6 5 . 2}$ \\
\hline
\end{tabular}

degraded, the Bufalin loaded in it was slowly released into blood, leading to prolonged residence of Bufalin in blood circulation, slower clearance and higher AUC. Therefore, it could be concluded that Bufalin-BSA-NP could improve the availability of Bufalin by prolonging drug retention and more tissue uptake in vivo. The pharmacokinetic study showed that the average particle size of Bufalin-BSA$\mathrm{NP}$ was about $125.1 \mathrm{~nm}$. Its half-life, average retention time, AUC and apparent volume of distribution were significantly higher than that of Bufalin group, whereas the clearance rate was lower than Bufalin group. The above results indicated that Bufalin-BSA-NP eliminates in the blood more slowly than Bufalin. And it can maintain blood drug concentration in a long time with sustained release properties in vivo.

The results of tissue distribution showed that Bufalin targeting liver tissue is apparent. On one hand, there is high drug concentration in liver tissue. One the other hand, high concentrations of drugs in the liver tissue sustained for a long time. However, the drug content of Bufalin-BSA-NP and Bufalin group in liver tissue were higher than normal liver tumor tissue, the possible reasons are molding and sampling. The cause may be the blood supply of normal liver tissue is greater than that of tumor tissue in liver. This is still a certain difference with the actual clinical pathology of hepatic carcinoma. In addition, the result also showed drug content of Bufalin-BSA-NP in liver tumors is higher than that of Bufalin, which showed Bufalin-BSA-NP have certain targets for liver tumors compared with Bufalin. The experimental results of another phenomenon is worthy of attention is that Bufalin group of drug content is very low in the spleen, but Bufalin-BSA-NP group's drug concentration in the spleen is higher than that of Bufalin. This may be related to the spleen and liver belong to the reticuloendothelial system rich in viscera. Particle size of nanoparticles is easily taken by RES between 100-200 nm.

The results of in vitro antitumor activity suggested that the process of preparation of bovine serum albumin nanoparticle did not destroy the antitumor activity of Bufalin. Therefore, Bufalin-BSA-NP and Bufalin have similar antitumor activity in vitro.

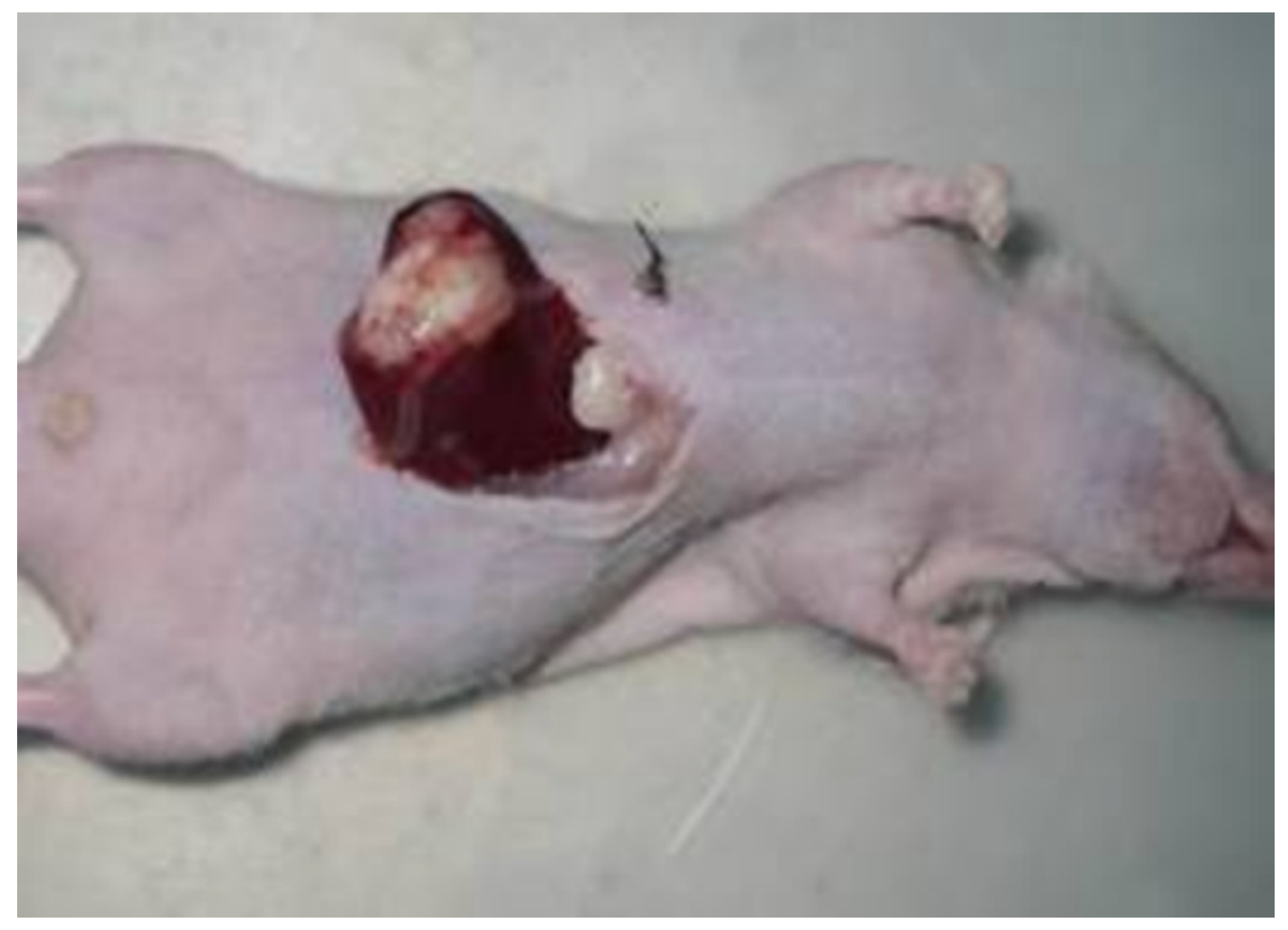

Figure 7: The nude mice orthotopic transplantation tumor model (10 days after transplantation). 
As illustrated in Figure 6, the average survival time of the mice with orthotopic transplantation liver cancer model administered Bufalin-BSA-NP and Bufalin have been extended $(P<0.05)$. Moreover, there were significant differences in the survival time of Bufalin-BSA-NP group and Bufalin group $(34.0 \pm 8.4 \mathrm{~d}$ versus $31.0 \pm 6.5 \mathrm{~d}$, $\mathrm{P}<0.01)$. However, the difference was not statistically significant $(P>0.05)$. Compared with NS group, ADM group did not prolong survival time without statistically significant difference.

The present results thus suggest that Bufalin-BSANP may become a promising drug delivery system for hepatocarcinoma targeting therapy.

\section{MATERIALS AND METHODS}

\section{Materials}

Bufalin, Cinobufagin, bovine serum albumin (BSA), 3-(4, 5-dimethyl-2-thiazyl)-2, 5-diphenyl-2Htetrazolium bromide (MTT), glutaraldehyde and dimethyl sul-foxide (DMSO) were purchased from Sigma-Aldrich (St Louis, MO, USA). Acetonitrile and methyl alcohol were purchased from Fisher Scientific (Pittsburgh, PA, USA). High-glucose Dulbecco's Modified Eagle's Medium (DMEM), Fetal Bovine serum (FBS), Pancreatic enzyme and Ethylene Diamine Tetraacetic Acid (EDTA) were purchased from Hyclone Laboratories (Logan, UT, USA). Adriamycin was purchased from Wanle Pharmacia (Shenzhen, China). Pentobarbital sodium was obtained from Merck Corp (Darmstadt, Germany). All solvents were of high-performance liquid chromatogra-phy grade. All reagents were of analytical grade.

\section{Preparation of Bufalin-BSA-NP}

$50 \mathrm{mg}$ bovine serum albumin was dissolved in water while $5 \mathrm{mg}$ Bufalin was dissolved by $95 \%$ mlethyl alchohol. Both two types of solution were homogeneous and transparent. Then under $\mathrm{pH}$ value of 5-7, Bufalin solution was added into bovine serum albumin aqueous solution. While continuous stirring, specific amount of 95\% ethyl alchohol acting as dehydrant was added into the above mixed solution with a constant injection speed of $0.8 \mathrm{ml} / \mathrm{min}$. After transparent emulsion formed, cross-linking agent $4 \%$ glutaraldehyde was applied to solidify the Bufalin-BSA-NP, then stirring it for 24 hours, Organic solvents such as ethyl alcohol were removed by underpressure evaporation, the remained solution volume was precisely determined.

\section{Characterization of Bufalin-BSA-NP}

Particle morphology was investigated by TEM after negative stained with phosphonic acid wolfram. The average particle size, particle size distribution and Zeta potential of Bufalin-BSA-NP were determined by laser light scattering method. The as prepared Bufalin-BSA-NP emulsion was centrifugated $\left(10,000 \mathrm{rpm} / \mathrm{min}, 4^{\circ} \mathrm{C}\right)$ for 30 min to acquire desalinized Bufalin-BSA-NP in the lower layer and free Bufalin solution in the up layer, of which the amount of Bufalin was measured by reverse-phase high-performance liquid chromatography (RP-HPLC, Hitachi Co., Tokyo) method. Encapsulation efficiency (EE\%) and drug loading (DL\%) were worked out by following equations: $\mathrm{EE} \%=$ Bufalin in Bufalin-BSA-NP/ total Bufalin $\times 100 \%$; DL $\%=$ Bufalin in Bufalin-BSANP/weight of Bufalin-BSA-NP $\times 100 \%$; where the weight of Bufalin-BSA-NP is equal to albumin plus Bufalin in Bufalin-BSA-NP.

Dialysis bag containing desalinized Bufalin-BSANP emulsion was put into $100 \mathrm{ml}$ of phosphate buffer $(\mathrm{pH}$ 7.4). The buffer solution was oscillated in thermostatic oscillator $\left(37 \pm 1^{\circ} \mathrm{C}, 50 \pm 1\right.$ shake frequency/min). At a specific time, $1 \mathrm{ml}$ of suspension was taken out and the concentration of Bufalin was then measured with RPHPLC. Finally, the accumulative release rate could be calculated with the concentration data measured.

\section{Acute toxicity test}

Acute toxicity test of Bufalin-BSA-NP and Bufalin was investigated in Kunming mice (aged 3 weeks, weighing $20 \pm 1.0 \mathrm{~g}$ ), provided by the experimental animal center of the Second Military Medical University (Shanghai, China). This study protocol has been approved by the ethical review boards of Second Military Medical University. Animal welfare and experimental procedures were carried out in accordance with the guide for the care and use of laboratory animals and related ethical regulations of National Research Council's Guide for the use of laboratory animals. The mice were randomly assigned into 14 groups, with five females and five males in each group. Bufalin-BSA-NP and Bufalin were given respectively to the mice at dosages of $8,5.81,4.23,3.09$, $2.25,1.64$ and $1.20 \mathrm{mg} / \mathrm{kg}$ (relative concentration of Bufalin). All mice were injected in the caudal vein by 0.2 $\mathrm{ml}$ and calculated the number of lives lost. The median lethal dose $\left(\mathrm{LD}_{50}\right)$ values were evaluated by Bliss method [30]. The organic tissue of heart, liver, spleen, lung and kidney were collected from dead mice quickly and fixed in $10 \%(\mathrm{v} / \mathrm{v})$ neutral formalin solution. Twenty-four hours post-injection, all the mice were euthanized and organs were harvested and fixed as stated above. The pathological changes of important organs were studied by hematoxylineosin (HE) staining.

\section{Pharmacokinetic and biodistribution studies}

The analyses were performed on an Agilent 1200 series high-performance liquid chromatography (HPLC) and an Agilent 6410 triple-quadrupole mass spectrometer equipped with an electro-spray ionization source (Agilent Technologies, MA, USA). The mobile 
phase was acetonitrile-water $(65: 35, \mathrm{v} / \mathrm{v})$ containing $0.1 \%$ formic acid. A DIKMA Inertsil ODS-3 column $(150 \mathrm{~mm} \times 2.1 \mathrm{~mm}, 5 \mu \mathrm{m})$ with an Agilent Zorbax SBC18 column $(100 \mathrm{~mm} \times 2.1 \mathrm{~mm}, 3.5 \mu \mathrm{m})$ was used for liquid chromatographic separation. The column was equilibrated and eluted under isocratic conditions with a flow rate of $0.3 \mathrm{~mL} / \mathrm{min}$, maintained at $35^{\circ} \mathrm{C}$. The sample injection volume was $10 \mu \mathrm{L}$ and the run time was 2.2min. Quantification was performed in negative multiple reaction monitoring (MRM) of the transitions $\mathrm{m} / \mathrm{z} 387.2$ $\rightarrow 255.1$ for Bufalin (Figure 1A and $1 \mathrm{C}$ ) and $\mathrm{m} / \mathrm{z} 443.2 \rightarrow$ 365.1 for the internal standard (IS, Cinobufagin, Figure $1 \mathrm{~B}$ and 1D). The detection parameters were optimized as follows: drying gas temperature, $350^{\circ} \mathrm{C}$; drying gas flow, $10 \mathrm{~L} / \mathrm{min}$; nebulizer pressure, $40 \mathrm{psi}$; capillary voltage, $4000 \mathrm{~V}$; fragmentor voltage, $180 \mathrm{~V}$ for Bufalin and $135 \mathrm{~V}$ for the IS; collision energy, $22 \mathrm{eV}$ for Bufalin and $18 \mathrm{eV}$ for the IS (Table 2).

The pharmacokinetic and biodistribution studies were performed on Wistar rats bearing Walker-256 transplanted liver cancer [31]. Walker-256, a rat hepatoma cell line (inoculated with breast cancer cells to the liver tumor), is similar to human liver cancer in blood supply and growth behavior after liver transplantation, and has been widely applied in experimental treatment, metastasis and pharmacokinetic of HCC [32].

Six group of rats for pharmacokinetic were intravenously administered with Bufalin or Bufalin-BSA$\mathrm{NP}$ at different doses $(0.6,0.3$ and $0.15 \mathrm{mg} / \mathrm{kg})$, and blood samples were collected from postorbital venous plexus veins at selected time points $(1,5,8,10,15,20,30,45$, $60,120,180,300$ and $480 \mathrm{~min}$ ) on same rats. Blood samples were collected in heparinized tubes, and spun down at $3500 \mathrm{rpm} / \mathrm{min}$ for $10 \mathrm{~min}$ to isolate plasma, and the plasma samples were stored at $-80^{\circ} \mathrm{C}$ until analysis. Two groups of rats for biodistribution were intravenously administered with Bufalin or Bufalin-BSA-NP at dose of $0.3 \mathrm{mg} / \mathrm{kg}$. Organs (liver, heart, lung, spleen, kidney and brain) and tumor tissue were harvested, weighed, rinsed and homogenated in normal saline. All of blood samples and homogenate were centrifuged $(3500 \mathrm{rpm} / \mathrm{min})$, and the supernatant was stored at $-80^{\circ} \mathrm{C}$ until analysis. $20 \mu \mathrm{L}$ of internal standard (Cinobufagin, $200 \mathrm{ng} / \mathrm{ml}$ ) was added to $100 \mu \mathrm{L}$ of plasma or supernatant sample. The mixture was vortexed for $0.5 \mathrm{~min}$ and $2.5 \mathrm{ml}$ ethylene acetate was added centrifuged at $3500 \mathrm{rpm} / \mathrm{min}$ for $10 \mathrm{~min}$. Then $2 \mathrm{ml}$ of the supernatant was collected and evaporated to dryness at $45^{\circ} \mathrm{C}$ and the residue was then redissolved in mobile phase $(100 \mu \mathrm{L})$. Then, a $10 \mu \mathrm{L}$ aliquot of supernatant was injected into the HPLC-MS/MS system.

\section{Antitumor activity in vitro}

Human hepatoma cell line (SMMC-7721), provided by Shanghai Cellular Institution of Chinese Science
Academy, were grown in DMEM containing 10\% FBS and kept at $37^{\circ} \mathrm{C}$ in a humidified incubator with $5 \% \mathrm{CO}_{2}$ and $97 \%$ relative humidity. Cells were plated into a 96well plate at $1 \times 10^{4} / \mathrm{well}$, and cultured routinely for 24 h. $20 \mu \mathrm{L}$ of different concentrations of Bufalin-BSA-NP and Bufalin solution diluted by DMEM $+10 \%$ FBS were added into according ditch in experimental groups. Same volume of tumor cells served as a negative control. There were five pores of each group of each concentration. At 48 h point of culture, $20 \mu \mathrm{L}$ of MTT was added in and then continued to culture for $4 \mathrm{~h}$. The supernatant was discarded and $100 \mu \mathrm{L}$ of DMSO was added, oscillated until full dissolution, absorption (A) was determined by ELLISA at $570 \mathrm{~nm}$. Cell survival was evaluated by the MTT method and is reported as $\mathrm{IC}_{50}$, i.e., the concentration (micromoles per liter) of the test compound that inhibits $50 \%$ of cell growth. The cell viability was calculated by using the formula: ([ES - BC] / [US - BC]) $\times 100 \%$. ES, US and BC were defined as the absorbance of experimental samples, untreated samples and blank controls, respectively.

\section{Antitumor activity in vivo}

The nude mice orthotopic transplantation tumor models were established by using the intrahepatic tunnel implantation [33]. The SMMC-7721 cells $\left(2 \times 10^{6}\right.$ cells $)$ were injected subcutaneously into nude mice to construct implanted tumors. When the tumor reached diameter of 1 $\mathrm{cm}$ it was dissected and cut into pieces of around $2 \times 2 \times 1$ $\mathrm{mm}^{3}$. These pieces were transplanted into the capsule of the left lateral liver lobe of another nude mouse. The figure of the nude mice orthotopic transplantation tumor model (10 days after transplantation) was showed in Figure 7. After he nude mice orthotopic transplantation tumor models have been made sucessfully, sixty mice were equally randomized into four groups: Bufalin-BSANP group, Bufalin group, positive group (ADM group) and negative group (NS group) $(\mathrm{n}=15)$. Bufalin-BSANP and Bufalin were injected intravenously at dose of $1 \mathrm{mg} / \mathrm{kg}$ for day 14 to day 23 after establishment of the model. NS group were injected equal volume normal saline as above. Adriamycin were injected intravenously into ADM group at dose $8.0 \mathrm{mg} / \mathrm{kg}$ at day 14 . Ten mice in each group were killed at day 24 by cervical dislocation and the tumors tissue were removed and detected the volumes. Five mice in each group were kept alive for observation of tumor-bearing survival. The longest diameter (a) and short diameter (b) of the tumor body were measured by using a slide gaud, and the tumor volume was calculated according the formula $\mathrm{V}=\mathrm{ab}^{2} / 2$; the tumor inhibitory rate $=(1-$ mean tumor volume of the drug group / mean tumor volume of the control group $) \times 100 \%$; prolonged survival $=($ mean days of survival of the drug group / mean days of survival of the control group -1$) \times 100 \%$. 


\section{Statistical analysis}

Group differences in continuous variables were calculated with Student t-test. One-way ANOVA with the Dunnett's or Newman Keuls post-test was used to compare the means of three or more groups. $P<0.05$ was considered statistically significant. Data in this study were analyzed by using the software SPSS 21.0 (SPSS Inc., IL, USA).

\section{Abbreviations}

Bufalin-BSA-NP: Bufalin-loaded bovine serum albumin nanoparticle; BSA: Bovine serum albumin; HCC: hepatocellular carcinoma; TCM: traditional Chinese medicine; AUC: area under the curve; MRT: mean residence time; ADM: adriamycin; NS: normal saline; $\mathrm{t}_{1 / 2}$ : half-life of plasma; $C_{\max }:$ maximum concentration; Vd: aparent volume of distribution; CL: clearance; RES: reticulate endothelial system.

\section{Author contributions}

Huiqing Zhang and Nian Huang have contributed equally to this work.

\section{ACKNOWLEDGMENTS}

This work was supported by grants from the National Natural Science Foundation of China (No. 81673739) and the Medical Research Fund of Shanghai Municipal Health and Family Planning Commission (No. 201440365, No.ZY3- RCPY-3-1058).

\section{CONFLICTS OF INTEREST}

The authors declare no conflicts of interest in this work.

\section{REFERENCES}

1. Siegel RL, Miller KD, Jemal A. Cancer statistics, 2016. CA Cancer J Clin. 2016; 66: 7-30. doi: 10.3322/caac.21332.

2. Chen $\mathrm{CH}, \mathrm{Su}$ WW, Yang SS, Chang TT, Cheng KS, Lin $\mathrm{HH}$, Wu SS, Lee CM, Changchien CS, Chen CJ, Sheu JC, Chen DS, Lu SN. Long-term trends and geographic variations in the survival of patients with hepatocellular carcinoma: analysis of 11,312 patients in Taiwan. J Gastroenterol Hepatol. 2006; 21: 1561-6. doi: 10.1111/j.1440-1746.2006.04425.x.

3. Chang HC, Lin YM, Yen AM, Chen SL, Wu WY, Chiu SY, Fann JC, Lin YS, Chen HH, Liao CS. Predictors of longterm survival in hepatocellular carcinomas: a longitudinal follow-up of 108 patients with small tumors. Anticancer Res. 2013; 33: 5171-8. doi: 10.1111/j.1440-1746.2006.04425.x.
4. Llovet JM, Bruix J. Novel advancements in the management of hepatocellular carcinoma in 2008. J Hepatol. 2008; 48: S20-37. doi: 10.1016/j.jhep.2008.01.022.

5. Mehta RG, Murillo G, Naithani R, Peng X. Cancer chemoprevention by natural products: how far have we come? Pharm Res. 2010; 27: 950-61. doi: 10.1007/ s11095-010-0085-y.

6. Wang X, Wang N, Cheung F, Lao L, Li C, Feng Y. Chinese medicines for prevention and treatment of human hepatocellular carcinoma: current progress on pharmacological actions and mechanisms. J Integr Med. 2015; 13: 142-64. doi: 10.1016/S2095-4964(15)60171-6.

7. Zhai XF, Chen Z, Li B, Shen F, Fan J, Zhou WP, Yang YK, Xu J, Qin X, Li LQ, Ling CQ. Traditional herbal medicine in preventing recurrence after resection of small hepatocellular carcinoma: a multicenter randomized controlled trial. J Integr Med. 2013; 11: 90-100. doi: 10.3736/jintegrmed2013021.

8. Zhang DM, Liu JS, Tang MK, Yiu A, Cao HH, Jiang L, Chan JY, Tian HY, Fung KP, Ye WC. Bufotalin from Venenum Bufonis inhibits growth of multidrug resistant HepG2 cells through G(2)/M cell cycle arrest and apoptosis. Eur J Pharmacol. 2012; 692: 19-28. doi: 10.1016/j. ejphar.2012.06.045.

9. Chen G, Jiang X, Li J, Duan G, Yang L, Zhang Y, Wang F. Study on anti-osteosarcoma activity of ethanol extract of Venenum bufonis in vitro. Afr J Tradit Complement Altern Med. 2014; 11: 73-7.

10. Lu CX, Nan KJ, Lei Y. Agents from amphibians with anticancer properties. Anticancer Drugs. 2008; 19: 931-9. doi: 10.1097/CAD.0b013e3283139100.

11. Meng Z, Yang P, Shen Y, Bei W, Zhang Y, Ge Y, Newman RA, Cohen L, Liu L, Thornton B, Chang DZ, Liao Z, Kurzrock R. Pilot study of huachansu in patients with hepatocellular carcinoma, nonsmall-cell lung cancer, or pancreatic cancer. Cancer. 2009; 115: 5309-18. doi: 10.1002/cncr.24602.

12. Miao Q, Bi LL, Li X, Miao S, Zhang J, Zhang S, Yang Q, Xie YH, Zhang J, Wang SW. Anticancer effects of bufalin on human hepatocellular carcinoma HepG2 cells: roles of apoptosis and autophagy. Int J Mol Sci. 2013; 14: 1370-82. doi: 10.3390/ijms14011370.

13. Xie CM, Chan WY, Yu S, Zhao J, Cheng CH. Bufalin induces autophagy-mediated cell death in human colon cancer cells through reactive oxygen species generation and JNK activation. Free Radic Bio Med. 2011; 51: 1365-75. doi: 10.1016/j.freeradbiomed.2011.06.016.

14. Jiang YT, Zhang Y, Luan JL, Duan HY, Zhang F, Yagasaki $\mathrm{K}$, Zhang GY. Effects of bufalin on the proliferation of human lung cancer cells and its molecular mechanisms of action. Cytotechnology. 2010; 62: 573-83. doi: 10.1007/ s10616-010-9310-0.

15. Takai N, Ueda T, Nishida M, Nasu K, Narahara H. Bufalin induces growth inhibition, cell cycle arrest and apoptosis in 
human endometrial and ovarian cancer cells. Int J Mol Med. 2008; 21: 637-43.

16. Amano Y, Cho Y, Matsunawa M, Komiyama K, Makishima M. Increased nuclear expression and transactivation of vitamin D receptor by the cardiotonic steroid bufalin in human myeloid leukemia cells. J Steroid Biochem. 2009; 114: 144-51. doi: 10.1016/j.jsbmb.2009.01.022.

17. Li D, Qu XJ, Hou KZ, Zhang Y, Dong Q, Teng Y, Zhang JD, Liu YP. PI3K/Akt is involved in bufalin-induced apoptosis in gastric cancer cells. Anticancer Drugs. 2009; 20: 59-64. doi: 10.1097/CAD.0b013e3283160fd6.

18. Qiu YY, Hu Q, Tang QF, Feng W, Hu SJ, Liang B, Peng W, Yin PH. MicroRNA-497 and bufalin act synergistically to inhibit colorectal cancer metastasis. Tumour Biol. 2014; 35: 2599-606. doi: 10.1007/s13277-013-1342-6.

19. Gu W, Liu L, Fang FF, Huang F, Cheng BB, Li B. Reversal effect of bufalin on multidrug resistance in human hepatocellular carcinoma BEL-7402/5-FU cells. Oncol Rep. 2014; 31: 216-22. doi: 10.3892/or.2013.2817.

20. Toma S, Hirai Y, Sugimoto C, Shoji M, Oguni Y, Morishita S, Ito C, Horie M. [Metabolic fate of bufalin in rats]. [Article in Japanese]. Yakugaku Zasshi 1991; 111: 676-86.

21. Xia H, Gao X, Gu G, Liu Z, Zeng N, Hu Q, Song Q, Yao L, Pang Z, Jiang X, Chen J, Chen H. Low molecular weight protamine-functionalized nanoparticles for drug delivery to the brain after intranasal administration. Biomaterials. 2011; 32: 9888-98. doi: 10.1016/j.biomaterials.2011.09.004.

22. Kim SS, Rait A, Rubab F, Rao AK, Kiritsy MC, Pirollo KF, Wang S, Weiner LM, Chang EH. The clinical potential of targeted nanomedicine: delivering to cancer stem-like cells. Mol Ther. 2014; 22: 278-91. doi: 10.1038/mt.2013.231.

23. Davis ME, Chen ZG, Shin DM. Nanoparticle therapeutics: an emerging treatment modality for cancer. Nat Rev Drug Discov. 2008; 7: 771-82. doi: 10.1038/nrd2614.

24. Patel NR, Pattni BS, Abouzeid AH, Torchilin VP. Nanopreparations to overcome multidrug resistance in cancer. Adv Drug Deliv Rev. 2013; 65: 1748-62. doi: 10.1016/j.addr.2013.08.004.
25. Li M, Zhang WY, Wang BR, Gao Y, Song ZF, Zheng QC. Ligand-based targeted therapy: a novel strategy for hepatocellular carcinoma. Int J Nanomed. 2016; 11: 564569. doi: 10.2147/Ijn.S115727.

26. Kratz F. Albumin as a drug carrier: design of prodrugs, drug conjugates and nanoparticles. J Control Release. 2008; 132: 171-83. doi: 10.1016/j.jconrel.2008.05.010.

27. Tantra R, Tompkins J, Quincey P. Characterisation of the de-agglomeration effects of bovine serum albumin on nanoparticles in aqueous suspension. Colloids Surf B Biointerfaces. 2010; 75: 275-81. doi: 10.1016/j. colsurfb.2009.08.049.

28. Iyer AK, Khaled G, Fang J, Maeda H. Exploiting the enhanced permeability and retention effect for tumor targeting. Drug Discov Today. 2006; 11: 812-8. doi: 10.1016/j.drudis.2006.07.005.

29. Liechty WB, Peppas NA. Expert opinion: responsive polymer nanoparticles in cancer therapy. Eur J Pharm Biopharm. 2012; 80: 241-6. doi: 10.1016/j. ejpb.2011.08.004.

30. Yuan G, Dai S, Yin Z, Lu H, Jia R, Xu J, Song X, Li L, Shu Y, Zhao X. Toxicological assessment of combined lead and cadmium: acute and sub-chronic toxicity study in rats. Food Chem Toxicol. 2014; 65: 260-8. doi: 10.1016/j. fct.2013.12.041.

31. Botelho NM, Correa SC, Lobato RC, Teixeira RK, Quaresma JA. Immunohistochemistry of the uterine cervix of rats bearing the Walker 256 tumor treated with copaiba balsam. Acta Cir Bras. 2013; 28: 185-9.

32. Jin Y, Tong D, Shen J, Yang J, Li J. Establishment of experimental implantation tumor models of hepatocellular carcinoma in Wistar rats. Tumour Biol. 2014; 35: 9079-83. doi: 10.1007/s13277-014-2161-0.

33. Zhang W, Sun HC, Wang WQ, Zhang QB, Zhuang PY, Xiong YQ, Zhu XD, Xu HX, Kong LQ, Wu WZ, Wang L, Song TQ, Li Q, et al. Sorafenib down-regulates expression of HTATIP2 to promote invasiveness and metastasis of orthotopic hepatocellular carcinoma tumors in mice. Gastroenterology. 2012; 143: 1641-9. e5. doi: 10.1053/j. gastro.2012.08.032. 